\title{
IMPACT OF OPEN CAST COAL MINING ON AVERAGE DECREASE OF NUMBER OF SOIL INSECTS IN MINING AREAS OF JHARIA COAL FIELD IN COMPARISON TO NON-MINING AREAS OF DHANBAD (JHARKHAND)
}

\author{
NILESH KUMAR SINGH ${ }^{* *}$ and S. K. SINHA ${ }^{2}$ \\ ${ }^{\prime}$ Rajiv Gandhi Mem. T. T. College, BBMKU, Dhanbad (Jharkhand) \\ ${ }^{2}$ Department of Zoology, BBMKU, Dhanbad (Jharkhand)
}

\begin{abstract}
In Jharia coalfield coal is being extracted through opencast mining. Open cast mining directly hampers the important vegetative layer i.e. upper layer of the soil. Due to open cast mining the natural habitats of several microorganisms and soil insects are being completely destroyed. This paper presents the results of the study carried out in both mining and non-mining areas. To assess the impact of open cast coal mining on available soil insects multiple samples were collected from both mining and non-mining areas. Abundance, density and number of identified soil insects were calculated and compared minutely.
\end{abstract}

Key words : Mining, Opencast, Vegetative layer, Abundance, Density.

\section{INTRODUCTION}

Mining activity in Jharia coalfield (JCF) was started in 1895 but large scale mining started in 1920 . The Geological Survey of Jharia Coalfield was done in 1930 by C. S. Fox. Opencast mines in Jharia coalfield were owned by local or private owners operating in very small patches for small units (Sharma and Raju,2007). During 1971-73 in Jharia coalfield, coal was prominently exploited in unscientific way by the local or private owners due to which many problems arose for example loss of livelihood, loss of human health, loss of habitats and fire problems etc.

In Jharia coalfield open cast mining is being done on large scale due to which formation of overburden dumps takes place. It is estimated that approximately 750 hectare land per year is required for overburden dumps around mining areas (Kundu and Ghosh,1994). The overburden dumps change the natural topography. It also affects the drainage system of soil and prevent natural succession of plant growth.

\section{MATERIAL AND METHODS}

Description of the sampling sites : Bastacola and Lodna of Jharia coalfield had been selected as sampling sites for mining areas whereas Baliapur and Sindri had been selected as sampling sites for non-mining areas. From each mining and nonmining area 5 soil samples had been collected.

Field work : The study area was divided into mining (Bastacola and Lodna) and non-mining (Baliapur and Sindri ) sites to the impact of open cast coal mining. Soil samples were collected from each mining as well as non-mining area by making $30 \times 30 \times 12.5 \mathrm{~cm}$ pits randomly. The significant quantitative analysis such as abundance, density etc. of soil insects for both mining and non-mining areas were done as per Curtis and McIntosh (1950).
Soil sampling methods : The procedure of soil sampling was based on recommendations of physical, chemical and biological soil test procedures as suggested in the hand book of method in Environmental Studies, Vol. 2, Air, Noise, Soil and Overburden analysis by Maiti (2000)

Instruments used for insect of collection : 1 . Collecting bag or other container. 2. Insect nets, 3. Collecting jars (killing jars/alcohol vials), 4. Envelopes, 5. Forceps, 6. Beat sheet, 7. Aspirator, 8. Sifter/pan (for leaf litter)

Different types of Traps : 1. Pitfall traps, 2. Board traps, 3. Berlese funnel, 4. Bait trap, 5. Blacklight traps, 6. Pan traps.

Identification of soil insects : Soil insects were identified with the help of'Identification key' given in the books of Imms (Richards and Davies, 1978).

Total count of number of insects (By Quadrate method) : To know the number of organisms present in a particular habitat, counting a smaller representative part of the population is very important as it would not be feasible to count them all. The systematic use of quadrate was developed by the pioneering ecologists R. Pound and F. E. Clements between 1898 and 1900. The ecologists such as F. W. Oliver and A. G. Tansley in 1904 soon took up and modified the method. The ecologist J. E. Weaver applied the use of quadrate to the teaching of ecology in 1918 .

Population density :

Density $=$

Total number of individual(s) of the species in all the sampling unit (S)/Total number of sampling units studied (Q).

The value thus obtained is then expressed as number of individuals per unit area.

Abundance : It is explained as the number of individuals per quadrate of occurrence. 
Abundance $(A)=\frac{\text { Total number of individuals }}{\text { Number of quadrate of occurrence }}$

\section{Statistical analysis :}

Standard deviation : To calculate Standard Deviation following formula has been followed:

$\mathrm{SD}=\sqrt{\frac{\sum \mathrm{d}^{2}}{\mathrm{~N}}}$

Where,

$\mathrm{SD}=$ Standard Deviation; $\Sigma=$ Total $\mathrm{d}^{2}=$ Square of Deviation; $\mathrm{N}=$ Number of sources (Reichmann and Choudhary,1985).

Average percentage decrease in number of soil insect of mining areas in comparison to control (non-mining area) : Mean number of soil insects of all the mining sites along with control (non-mining sites) area have been obtained. To find out percentage decrease in number of soil insects for every selected mining site first the difference in mean number as compared to control area have been calculated then it has been di- vided by mean number of soil insect found in control area. To have percentage decrease it has been multiplied by 100 .

Percentage decrease in number of identified soil insect of a specific mining site $=$ Difference in mean number of identified soil insect as compared to control area x 100 / Mean number of identified soil insect calculated for control area

\section{RESULTS AND DISCUSSION}

The soil insects found in mining and non mining areas were calculated by 'Quadrate Method' very minutely and the results are tabulated in Tables. $1 \& 2$.

Fig. 1 shows that abundance of soil insect is far better in non-mining sites in comparison to mining of JCF.

Fig. 2 shows clearly indicates that density of soil insects in non-mining areas of Baliapur and Sindri is in excellent condition but mining areas of JCF are severely affected.

It has been observed that following soil insects of mining areas are heavily affected in terms of average percentage decrease in their numbers as compared to control area (Fig.3).

Table. 1 Soil insects collected from mining areas during post monsoon season (Mean \pm S. D.).

\begin{tabular}{|c|c|c|c|c|c|c|c|c|c|c|c|}
\hline S. & Name of soil insects & M S1 & M S2 & M S3 & M S4 & M S5 & M S6 & M S7 & M S8 & M S9 & $\overline{M ~ S 10}$ \\
\hline 1. & Termite & $2 \pm 0.77$ & $2 \pm 0.82$ & & $1 \pm 0.92$ & & $2 \pm 0.88$ & $1 \pm 0.44$ & & $2 \pm 0.09$ & $2 \pm 0.89$ \\
\hline 2. & Carpenter Ant & $2 \pm 0.72$ & . & $2 \pm 0.22$ & $1 \pm 0.28$ & $2 \pm 0.32$ & . & $3 \pm 0.42$ & $2 \pm 0.27$ & . & $1 \pm 0.43$ \\
\hline 3. & Little Black Ant & . & & $1 \pm 0.63$ & $2 \pm 0.44$ & & $2 \pm 0.89$ & & $3 \pm 0.77$ & . & $1 \pm 0.26$ \\
\hline 4. & Pavement Ants & & $1 \pm 0.63$ & . & & $2 \pm 0.70$ & . & $1 \pm 0.27$ & $2 \pm 0.70$ & . & . \\
\hline 5. & Fire Ant & $1 \pm 0.44$ & . & . & $2 \pm 0.77$ & & . & $3 \pm 0.83$ &. & & $2 \pm 0.89$ \\
\hline 6. & Harvester ants & . & . & $2 \pm 0.44$ & . & $1 \pm 0.22$ & & $2 \pm 0.09$ & . & $3 \pm 1.09$ & . \\
\hline & Army ants & & & $3 \pm 0.77$ & & & $2 \pm 0.89$ & & & $3 \pm 1.73$ & . \\
\hline 8. & Click beetle & $4 \pm \dot{1.41}$ & $4 \pm 1.78$ & $3 \pm 1.24$ & $4 \pm 1.34$ & $3 \pm \dot{1.09}$ & $3 \pm 1.41$ & $4 \pm 1.54$ & $5 \pm 1.26$ & $3 \pm 0.82$ & $4 \pm 0.93$ \\
\hline $\begin{array}{l}0 . \\
9 .\end{array}$ & Green June beetle & & & & $1 \pm 0.83$ & $\begin{array}{c}0.1 .07 \\
.\end{array}$ & & & . & & $\begin{array}{c}\text { 4.0.93 } \\
.\end{array}$ \\
\hline 10. & Ground beetle & $4 \pm 1.18$ & $5 \pm 1.81$ & $4 \pm 1.21$ & $4 \pm 0.96$ & $3 \pm 1.01$ & $4 \pm 0.80$ & $3 \pm 0.92$ & $4 \pm 0.89$ & $4 \pm 0.98$ & $3 \pm 0.78$ \\
\hline 11. & Rove beetle & $4 \pm 0.86$ & $4 \pm 1.05$ & $5 \pm 1.23$ & $4 \pm 0.88$ & $3 \pm 0.65$ & $4 \pm 0.98$ & $3 \pm 0.51$ & $3 \pm 0.42$ & $4 \pm 0.43$ & $4 \pm 0.45$ \\
\hline 12. & Seedcorn beetle & $1 \pm 0.81$ & . & $2 \pm 0.92$ & & $1 \pm 0.90$ & $2 \pm 0.75$ & & $2 \pm 0.76$ & $1 \pm 0.91$ & $2 \pm 0.21$ \\
\hline 13. & Darkling beetles & $1 \pm 0.07$ & & $2 \pm 0.78$ & $2 \pm 0.46$ & & $1 \pm 0.12$ & $2 \pm 0.52$ & . & $2 \pm 0.19$ & $1 \pm 0.72$ \\
\hline 14. & Rose chafer & & $1 \pm 0.16$ & $1 \pm 0.73$ & & $1 \pm 0.27$ & $2 \pm 0.81$ & $2+0.02$ & $1 \pm 0.13$ & $2 \pm 0.53$ & $1 \pm 0.18$ \\
\hline 15. & Camel cricket & $1 \pm 0.45$ & $1 \pm 0.23$ & . & $2 \pm 0.16$ & . & $2 \pm 0.48$ & & $2 \pm 0.50$ & $1 \pm 0.23$ & $2 \pm 0.18$ \\
\hline 16. & Mole cricket & $3 \pm 0.87$ & $3 \pm 0.88$ & $4 \pm 0.49$ & $4 \pm 0.15$ & $4 \pm 0.29$ & $3 \pm 0.71$ & $4 \pm 0.46$ & $3 \pm 0.81$ & $5 \pm 0.91$ & $4 \pm 0.95$ \\
\hline 17. & Dung beetle & $1 \pm 0.02$ & & . & $1 \pm 0.12$ & & . & & $1 \pm 0.19$ & & . \\
\hline 18. & Springtail & & $2 \pm 0.40$ & . & $1 \pm 0.42$ & $2 \pm 0.52$ & & $1 \pm 0.16$ & $2 \pm 0.43$ & $1 \pm 0.18$ & $2 \pm 0.45$ \\
\hline 19. & Field cricket & $2 \pm 0.72$ & $2 \pm 0.27$ & $1 \pm 0.41$ & $2 \pm 0.30$ & & $1 \pm 0.10$ & & $2 \pm 0.06$ & & $2 \pm 0.21$ \\
\hline 20. & Earwig & $2 \pm 0.22$ & . & $1 \pm 0.15$ & $2 \pm 0.76$ & $1 \pm 0.25$ & . & . & $2 \pm 0.28$ & $2 \pm 0.18$ & $1 \pm 0.10$ \\
\hline & Abundance & $28 \pm 0.22$ & $25 \pm 0.16$ & $31 \pm 0.40$ & $33 \pm 0.12$ & $23 \pm 0.20$ & $28 \pm 0.26$ & $27 \pm 0.18$ & $34 \pm 0.42$ & $33 \pm 0.13$ & $32 \pm 0.41$ \\
\hline & Density per quadrat & $2.8 \pm 0.22$ & $2.5 \pm 0.18$ & $3.1 \pm 0.41$ & $3.3 \pm 0.12$ & $2.3 \pm 0.22$ & $2.8 \pm 0.28$ & $2.7 \pm 0.19$ & $3.4 \pm 0.43$ & $3.3 \pm 0.19$ & $3.2 \pm 0.43$ \\
\hline
\end{tabular}

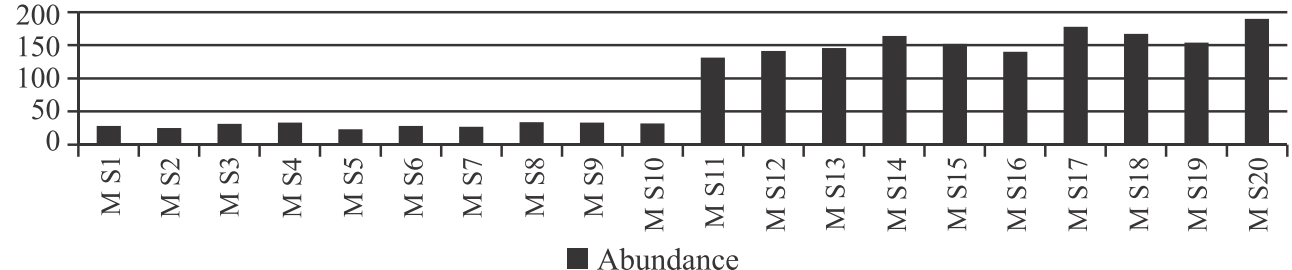

Fig. 1 Abundance of soil insect in selected sites of mining and non-mining areas. 
In mining area average percentage decrease in number of Termites was found $84.8 \%$, Carpenter Ants- $82.89 \%$, Little Black Ants-89.77\%, Pavement Ants-93.33\%, Fire Ants91.20\%, Harvester Ants-91.30\%, Army Ants-91.48, Click Beetles-60.20\%, Green June Beetles-98.43\%, Ground Beetles 55.80\%, Rove Beetles-47.94\%, Seedcorn Beetles82.25\%, Darkling Beetles-79.99\%, Rose Chafer-85.93\%, Camel Cricket-83.81\%, Mole Cricket-48.60\%, Dung Beetles $-96.58 \%$, Springtail- $85.89 \%$, Field Cricket- $84.60 \%$ and Earwigs- $84.72 \%$. Due to open cast mining the top most vegetative layer of the soil get severely damaged as a result of which essential physico-chemical characteristics of the soil get heavily affected which ultimately lead to degraded and unstable soil environment. In degraded and unstable soil environment of mining areas soil micro-organisms like bacteria, actinomycetes and fungi are also found in lowest number due to which the essential soil nutrients hardly remain available to plants and thus the natural habitat and the normal soil ecosystem of the mining area both get heavily damaged hence, the soil insects fail to be in good number. Soil insects have positive relation with the availability of healthy and balanced soil ecosystem which have good vegetation. Ideal and effective vegetation promote existence of soil organisms in non-mining areas as the barren dumps do not provide ideal conditions for soil organisms (CMRI, 1997).
Conclusion : Open cast mining has dangerously affected the soil environment of Bastacola and Lodna mining areas as it has caused land degradation, siltation of agricultural fields and loss of flora and fauna at great extent. In mining area lowest abundance i.e. 23 was found in MS5 (Kusunda Open Cast, Bastacola area No. IX of Jharia Coalfield) whereas the highest abundance i.e. 34 was found in MS8 (North Tisra Open Cast, Lodna area No. X of Jharia Coalfield). In non-mining area the lowest abundance i.e. 131 was found in NMS11 (Near DAV School, Rangamati of Baliapur area) and the highest abundance i.e. 190 was found in NMS20 (Sindri Basti of Sindri area). In mining area lowest density i.e. 2.3 insects per quadrat was found in MS5 (Kusunda Open Cast, Bastacola area No. IX of Jharia Coalfield) whereas the highest density i.e. 3.4 insects per quadrat was found in MS8 (North Tisra Open Cast, Lodna area No. X of Jharia Coalfield). In non-mining area the lowest density i.e. 13.1 insects per quadrat was found in NMS11 (Near DAV School, Rangamati of Baliapur) and the highest density i.e. 19.0 insects per quadrat was found in NMS20 (Sindri Basti of Sindri area). The present study reveals that abundance of soil insects in mining areas varied in between 23-34 whereas in non-mining areas it varied in between 131-190. The density of soil insects in mining areas varied in between 2.3-3.4 insects per quadrat and in non-mining areas the density of soil insects varied in between 13.1-19.0 in-

Table. 2 Soil insects collected from non-mining areas during post monsoon season (Mean \pm S. D.).

\begin{tabular}{|c|c|c|c|c|c|c|c|c|c|c|c|}
\hline S. & Name of soil insects & M S1 & M S2 & M S3 & M S4 & M S5 & M S6 & M S7 & M S8 & M S9 & M S10 \\
\hline 1. & Termite & $6 \pm 1.34$ & $7 \pm 1.67$ & $8 \pm 1.54$ & $7 \pm 1.73$ & $9 \pm 1.41$ & $8 \pm 1.61$ & $9 \pm 2.86$ & $6 \pm 1.83$ & $9 \pm 2.82$ & $10 \pm 1.09$ \\
\hline 2. & Carpenter Ant & $7 \pm 1.61$ & $8 \pm 1.78$ & $7 \pm 1.89$ & $8 \pm 1.73$ & $6 \pm 1.26$ & $7 \pm 1.84$ & $9 \pm 2.75$ & $8 \pm 1.67$ & $7 \pm 1.78$ & $9 \pm 2.79$ \\
\hline 3. & Little Black Ant & $9 \pm 1.48$ & $8 \pm 1.61$ & $8 \pm 1.84$ & $9 \pm 1.89$ & $7 \pm 1.67$ & $9 \pm 1.54$ & $10 \pm 1.09$ & $9 \pm 1.26$ & $9 \pm 1.34$ & $10 \pm 1.18$ \\
\hline 4. & Pavement Ants & $8 \pm 1.54$ & $9 \pm 1.78$ & $9 \pm 1.73$ & $8 \pm 1.54$ & $8 \pm 1.78$ & $10 \pm 1.18$ & $9 \pm 1.34$ & $8 \pm 1.41$ & $10 \pm 1.18$ & $11 \pm 1.78$ \\
\hline 5. & Fire Ant & $7 \pm 1.94$ & $8 \pm 1.94$ & $9 \pm 2.86$ & $8 \pm 1.54$ & $9 \pm 2.23$ & $11 \pm 2.56$ & $10 \pm 2.04$ & $9 \pm 2.86$ & $10 \pm 2.09$ & $10 \pm 2.04$ \\
\hline 6. & Harvester ants & $9 \pm 1.34$ & $9 \pm 1.54$ & $8 \pm 1.26$ & $9 \pm 1.41$ & $7 \pm 1.67$ & $10 \pm 1.26$ & $9 \pm 2.64$ & $11 \pm 2.14$ & $9 \pm 2.72$ & $11 \pm 2.19$ \\
\hline 7. & Army ants & $10 \pm 2.04$ & $9 \pm 2.86$ & $8 \pm 2.56$ & $10 \pm 2.44$ & $9 \pm 2.64$ & $8 \pm 2.82$ & $9 \pm 2.79$ & $10 \pm 2.32$ & $11 \pm 2.28$ & $10 \pm 2.0$ \\
\hline 8. & Click beetle & $7 \pm 1.54$ & $9 \pm 2.82$ & $9 \pm 2.86$ & $10 \pm 1.54$ & $9 \pm 1.41$ & $7 \pm 1.61$ & $12 \pm 2.86$ & $10 \pm 1.26$ & $8 \pm 1.94$ & $12 \pm 2.82$ \\
\hline & Green June beetle & $5 \pm 2.96$ & $6 \pm 1.41$ & $6 \pm 1.26$ & $8 \pm 1.94$ & $7 \pm 1.54$ & $5 \pm 2.79$ & $7 \pm 1.78$ & $7 \pm 1.73$ & $5 \pm 2.96$ & $8 \pm 1.73$ \\
\hline 10. & Ground beetle & $7 \pm 1.94$ & $8 \pm 1.48$ & $8 \pm 1.78$ & $10 \pm 2.04$ & $9 \pm 2.56$ & $7 \pm 1.89$ & $10 \pm 2.0$ & $9 \pm 2.64$ & $7 \pm 1.84$ & $11 \pm 1.54$ \\
\hline 11. & Rove beetle & $6 \pm 1.54$ & $6 \pm 1.48$ & $7 \pm 1.94$ & $9 \pm 2.75$ & $7 \pm 1.61$ & $5 \pm 2.89$ & $9 \pm 1.41$ & $8 \pm 1.54$ & $6 \pm 1.41$ & $10 \pm 1.26$ \\
\hline 12. & Seedcorn beetle & $5 \pm 2.96$ & $6 \pm 1.67$ & $6 \pm 1.18$ & $7 \pm 1.67$ & $7 \pm 1.73$ & $4 \pm 2.04$ & $7 \pm 1.78$ & $7 \pm 2.0$ & $6 \pm 1.09$ & $7 \pm 1.61$ \\
\hline 13. & Darkling beetles & $4 \pm 2.44$ & $5 \pm 2.75$ & $5 \pm 2.79$ & $7 \pm 1.54$ & $6 \pm 1.61$ & $4 \pm 2.48$ & $7 \pm 1.89$ & $6 \pm 1.26$ & $4 \pm 2.52$ & $7 \pm 1.78$ \\
\hline 14. & Rose chafer & $5 \pm 2.89$ & $5 \pm 2.52$ & $6 \pm 1.34$ & $7 \pm 2.0$ & $6 \pm 1.67$ & $5 \pm 2.96$ & $8 \pm 1.73$ & $8 \pm 1.67$ & $6 \pm 1.34$ & $8 \pm 1.73$ \\
\hline 15 . & Camel cricket & $5 \pm 2.89$ & $5 \pm 2.93$ & $7 \pm 1.67$ & $7 \pm 1.84$ & $6 \pm 1.09$ & $5 \pm 1.48$ & $9 \pm 2.75$ & $8 \pm 1.78$ & $7 \pm 1.73$ & $9 \pm 2.64$ \\
\hline 16. & Mole cricket & $6 \pm 1.18$ & $6 \pm 1.34$ & $7 \pm 1.67$ & $8 \pm 1.73$ & $7 \pm 1.94$ & $6 \pm 1.41$ & $9 \pm 2.56$ & $7 \pm 1.73$ & $6 \pm 1.67$ & $10 \pm 1.26$ \\
\hline 17. & Dung beetle & $6 \pm 1.18$ & $6 \pm 1.67$ & $8 \pm 1.84$ & $7 \pm 1.54$ & $9 \pm 2.89$ & $10 \pm 1.89$ & $9 \pm 2.56$ & $12 \pm 2.56$ & $11 \pm 2.14$ & $10 \pm 2.09$ \\
\hline 18. & Springtail & $6 \pm 1.48$ & $6 \pm 1.73$ & $7 \pm 1.89$ & $9 \pm 2.75$ & $10 \pm 1.09$ & $7 \pm 2.0$ & $9 \pm 2.79$ & $8 \pm 1.94$ & $7 \pm 1.0$ & $9 \pm 2.96$ \\
\hline 19. & Field cricket & $6 \pm 1.66$ & $7 \pm 1.41$ & $7 \pm 1.07$ & $9 \pm 2.96$ & $8 \pm 1.34$ & $6 \pm 1.53$ & $10 \pm 1.16$ & $8 \pm 1.37$ & $7 \pm 1.1$ & $10 \pm 1.16$ \\
\hline 20. & Earwigs & $7 \pm 1.78$ & $8 \pm 1.11$ & $6 \pm 1.66$ & $7 \pm 1.20$ & $6 \pm 1.41$ & $6 \pm 1.07$ & $7 \pm 1.34$ & $8 \pm 1.97$ & $9 \pm 1.53$ & $8 \pm 1.20$ \\
\hline & Abundance & $131 \pm 0.41$ & $141 \pm 0.42$ & $146 \pm 0.33$ & $164 \pm 0.31$ & $152 \pm 0.36$ & $140 \pm 0.20$ & $178 \pm 0.40$ & $167 \pm 0.32$ & $154 \pm 0.14$ & $190 \pm 0.41$ \\
\hline & Density per quac & $3.1 \pm 0.40$ & $1+$ & \pm 0.3 & $6.4 \pm 0.30$ & $5.2 \pm 0.3$ & $14.0 \pm 0.22$ & $17.8 \pm 0.42$ & $16.7 \pm 0.36$ & 0.16 & $9.0 \pm 0.4$ \\
\hline
\end{tabular}

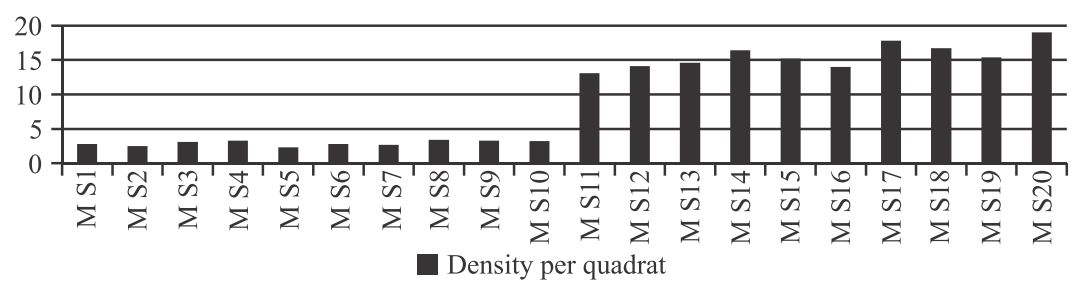

Fig. 2 Density of soil insect per quadrant in the selected sites of mining and non-mining areas. 


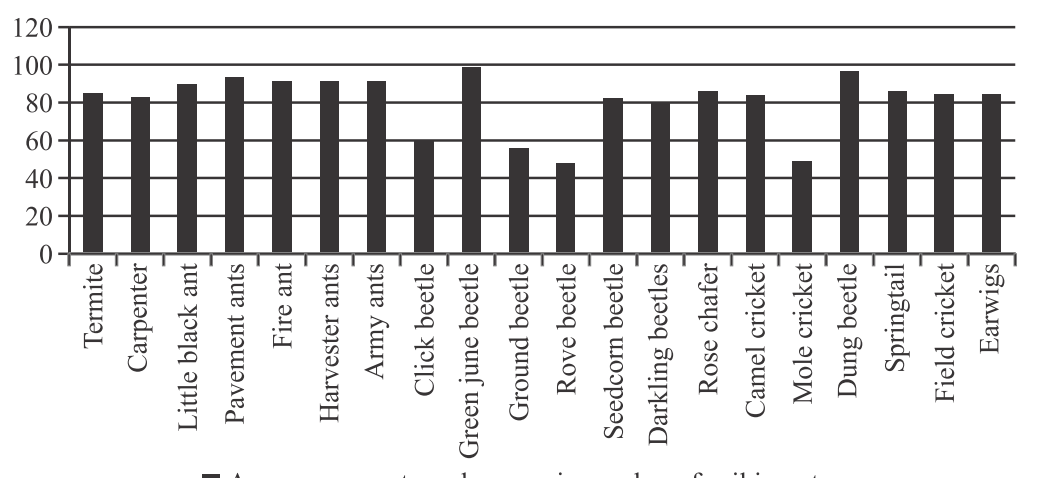

- Average percentage decrease in number of soil insects

Fig. 3 Average percentage decrease in number of soil insects in mining areas.

sects per quadrat hence the study proves that in non-mining areas (Baliapur \& Sindri) soil insects are present in excellent number but mining areas (Bastacola \& Lodna) due to harmful mining activities fail to provide ideal habitat to soil insects as a result of which occurrence of soil insects get affected severely.

The present study also reveals that the soil insects of mining areas (Bastacola \& Lodna) have average percentage decrease in their numbers when compared with control (nonmining) area of Baliapur \& Sindri. Green June Beetles of mining area have highest average percentage decrease in number i.e. $98.43 \%$ whereas Rove Beetles have lowest average per- centage decrease in number i.e. 47.94\% when compared with control area.

\section{ACKNOWLEDGMENTS}

The authors are highly grateful to the Director, B. I. T., Sindri, Dhanbad, Jharkhand for providing laboratory facility to carry out the research study. The authors also thank to General Manager, BCCL who allowed to visit the study areas at regular interval of time. The Department of Zoology, P. K. Roy, College, Dhanbad (Jharkhand), also provided all the facilities so authors are also very thankful to the Honorable Principal and the faculty members.

\section{REFERENCES}

Curtis, J. T. and Mc Intosh (1950). The inter relations of certain analytic and synthetic phytosociological characters, Ecology, 31 : $434-455$.

Fox, C. S. (1930). The Jharia Coalfields. Geological Survey of India, Bangalore, Vol. 56.

Kundu, N. K. and Ghosh, M. K. (1994). Impact of soil quality due to opencast Coal Project. In : Second National Seminar on Mineral Ecology. ISM, Oxford \& IBH Publication, Dhanbad.

Maiti (2000). Hand Book of Method in Environmental Studies : Vol. 2. Air, Noise, Soil and Overburden Analysis.

Oliver, F. W. and Tansley, A. G. (1904). Methods of Surveying Vegetation, $3: 228-237$.

Pound, R. and Clements, F. E. (1898). Minnesota Botanical Studies, 2 : 19-24.

Pound, R. and Clements, F. E. (1900). Phytogeography of Nebraska, 2 : 61-63.

Reichmann, Singh and Choudhary (1985). Statistical Analysis for Mean \& Standard Deviation, p. 317.

Richards, O. W. and Davies, R. G. (1978). Imms General Textbook of Entomology. Published By Chapman and Hall, 11 New Fetter Lane, London.

Sharma, B. K. and Raju, P. V. R. (2007). Environmental Management in Jharia Coalfields an Overview During Last Two Decades : Reinventing Jharia Coalfield, pp. 213-219.

Weaver, J. E. (1918). The Use of Quadrats for Teaching of Ecology. 